\title{
LA NUEVA LEY: UNIVERSIDAD Y SOCIEDAD EN EL PERU
}

\section{SITUACION ANTERIOR DE LA UNIVERSIDAD PERUANA}

La historia de los últimos años a pesar de su riqueza en acontecimientos, no parece arrojar un saldo favorable en las relaciones entre universidad y sociedad en el Perú. Las conquistas de la Reforma Universitaria se consignaron en la Ley 13417 - vigente hasta el 17 de febrero de este año-, y agotada en lo fundamental la fuente de conflictos que constituyeron la participación estudiantil en la proporción de un tercio en el gobierno de la universidad, el derecho de tacha y la tesis del paralelismo de las cátedras, sucedió una etapa de desgaste de los temas universitarios. Reemplazados momentáneamente a comienzos del régimen de Belaúnde, por un nuevo énfasis en el rol social de la universidad y su proyección en la comunidad, la naturaleza apenas reformista de esos intentos de comprometer a la universidad con el país, hizo que fueran dejados de lado rápidamente, en la medida que una vez más recobraba su vigencia indiscutida el único elemento permanente en la historia universitaria del presente siglo: la política.

No se trataba sin embargo, de un remedo de épocas anteriores. El último periodo se caracterizó por una dinámica diferente, donde los términos de referencia fueron puestos por los grupos políiticos más comprometidos con una utopía de transformación social, es decir por las izquierdas. Un observador imparcial reconoce - dadas las circunstancias socio-políticas de esta etapa- que el saldo no podía ser necesariamente positivo. La politización inorgánica de la Universidad, derivada sectaria, oscureció en muchos casos el ejercicio del papel político institucional, permitiendo que la imagen pública se corroyese. De otro lado, no era fácil el ejercicio de las funciones orientadoras de la universidad frenie a la sociedad, en mo- mentos que el fraccionamiento ideológico y partidario condicionaban a la universidad, convirtiéndola en virtual campo de batalla de grupos y tendencias.

Lo anterior, con importantes y específicas excepciones, puede explicar si no justificar, un cierto descuido por la universidad peruana de la importante misión que no el derecho - porque es la realidad la que crea el derecho y no a la inversa-, sino la historia te habian conferido: la critica social.

Y justamente fué la crítica social, el enjuiciamiento del sistema y de los procesos vividos en su interior, los síntomas que señalaron el cumplimiento de un papel ineludible a la universidad dentro de una sociedad transicional, subdesarrollada y dependiente. El compromiso, el diagnóstico, la reclamación y la denuncia, hicieron mucho en rescatar para la universidad un prestigio en decadencia, originada esta última por la declinación académica, la mediocridad de la enseñanza universitaria que perdía en calidad lo que ganaba en expansión y sobre todo por la ausencia de imaginación, de libertad $y$ de atrevimiento que impedía hacer ciencia propia y ratificaba la dependencia cultural de toda la sociedad.

En las condiciones descritas, la modernización de los años últimos y el aumento de recursos, no viabilizó medios para superar la crisis sino que institucionalizó curiosas formas de relación dispar. Entre la universidad privilegiada por el crédito externo, con ciudad universitaria, docencia de tiempo completo, equipamiento y tecnología contemporánea y en el otro lado, la desguarnecida universidad de provincia o la seudo-universidad particular, vista como negocio lucrativo frente a las desmesuradas expectativas creadas en la juventud, se abrió un abismo de oportunidades que estratificó internamente a la universidad, la mezcló en el debate político de los enfrentamientos regio- 
nales e hizo más evidente la impresión de caos al cotejarse los extremos.

\section{Crítica a la Universidad}

La situación expuesta no podría - sin injusticia evidente- ser achacada en forma exclusiva a la Universidad. En una interpretación ecológica que se insinúa, el organismo y su medio se condicionan mutuamente y a la vez intentan actuar uno sobre el otro, de modo de transformar la relación y aumentar su dominio relativo. Aplicando el símil a la relación universidadsociedad, se aprecia que la heterogeneidad de componentes en ambos extremos hace muy difícil simplificar. A pesar de ello es ilustrativo reiterar el rol diferente jugado por los grupos o sectores más relevantes para cada elemento.

En la sociedad, el predominio de los grupos interesados en mantener el orden vigente, debia llevar naturalmente a cuestionar el rol profético de la Universidad; en la práctica, a tratar de acallarla y desprestigiarla, por consiguiente explotar los enfrentamientos y magnificar las debilidades. Paralelamente y en forma casi contradictoria, aunque el fin fuese el mismo, el afén de tales grupos por controlar la Universidad, utilizando para este fin hasta la mecónica estatal y el manejo de recursos y privilegios. Otros sectores -cuestionando el orden aciual y reclamando su transformación-, opuestos a los anteriores, con menor repercusión y acceso al poder, tentaban el mismo objetivo de obtener el control sobre la Universidad, pero de manera más explicita. Unos aludian a una misión institucional con el país, otros en perspectivas más instrumentales, confundieron en muchos casos la atribución de un rol político con la politización de una institución. Esta confusión e imprecisión en Tos grupos politicos de ambos extremos sobre la vigencia y función de las instituciones en el seno de la sociedad, aparece como un hecho tanto más importante, cuanto más se acepte el ev:dente predominio de lo político en el sistema social, característico a la condición de subdesarrollo.

En la universidad, naturalmente se repetía la dicotomía - no tan simplificada- entre los partidarios del orden y del cambio, traducida a un enfoque o modelo de universidad. Desaparecido o acallado el conservador intransigente, la defensa del orden social actual, fue asumida por los "progresistas" miembros de los claustros nacionales, enarbolando la tesis del desarrollo por etapas, de la difusión cultural $y$ de la socialización en la "motivación de logro". En ese contexto, -bienvenido, prohijado y explícitamente patrocinado por la derecha y ef reformismo nacionales, tas universidades extranjeras y tos organismos y fundaciones internacionales-, las Universidades peruanas debían tender o aproximarse a un modelo de racionalidad. eficiente, apoliticismo y neutralidad ideológica/Contrastando con lo anterior, sectores que dentro de la universidad se angustiaban por la agravación sutilmente inexorable de la dependencia del país en todos los órdenes, y negaban la viabilidad de reformismos desarrollistas, exigian un rol de mucha mayor agresividad de parte de la universidad, el ejercicio pleno de la crítica social y el compromiso, no sólo a nivel de estudiantes o profesores, sine come institución, con la tarea de transformar y reconstituir el sistema social.

Esquematizada en esta forma la contradicción dentro y fuera de la Universidad, cabe añadir que la opinión pública nunca tuvo acceso sino fragmentario al nivel de fondo de la discrepancia. Resulta natural que los interesados en mantener el status social presente y destruir la tarea concientizante de la Universidad, lo callaran o minimizaran. Resulta incomprensible que los sectores opositores cayeran en el juego de las derechas, desperdiciaran la oporiunidad de autocriticarse y arriesgaran así una tarea trascendente de cuya verdad aparecian como depositarios.

Enfocado el problema desde el ángulo mayor de la responsabilidad social, no es discutible que autoridades, profesores y alumnos expusieron inevitablemente a la Universidad a la pérdida progresiva de consenso y legitimidad, es decir de voz autorizada, es decir de poder. De continuar el enviciamiento, aun en el nivel instrumental, quienes arriesgaban eran los partidarios de la transformación. La imagen negativa, proyectada y manipulada por los sectores dominantes, debía tomar fuerza descalificando a la Universidad, máxime cuando los altos fines perseguidos incluian la subversión social y la reconstitución del sistema. Cuando una institución se enfrenta a un sistema careciendo internamente de cohesión, de estrategia y de recupsos, y al mismo tiempo sacrifica en to externo sus factores de poder, tedas las cartas se juegan en su contra.

\section{La Ley Orgánica de la Universidad Peruana}

La dación del Decreto-Ley 17437 de 18 de febrero de 1969, sin pública consulta, a diferencia de otros importantes textos legales sometidos por el gobierno 
militar a comentario y opinión, tomó a la universidad por sorpresa y en vacaciones. En el desconcierto inicial, entre los comunicados-sintesis y una lectura rá. pida de los 170 artículos del texto legal, las reacciones se polarizaron entre quienes excelsaban la racionalización (planificación, programación, coordinación, ụnidad administrativa) y respeto a los valores académicos, y aquellos que presintiendo el retorno a la vigencia de los dudosos valores de orden y control, denunciaban el recorte de la autonomía, el desconocimiento de la participación estudiantil y la represión de la actividad politica.

El análisis a mayor profundidad de la nueva ley orgánica permite afirmar que algo mucho més serie que las "conquistas" de la reforma universitaria está en juego en las entrelíneas del decreto-ley 17437. Puesta sobre la mesa, condenada a desaparecer por la nueva ley, están una función v un rol social que comprometen la $\epsilon$ sencia misma de la institución. Está en discusión la naturaleza de la universidad, pero no como abstracción sino como el fruto histórico de una dialéctica permanente en que la sociedad y los institutos sociales se condicionan mutuamente. De la historia nacional surge un consenso sobre la universidad, que en circunstancias diversas le confiere funciones muy altas, entre ellas, la de trinchera social aún cuando la institución atraviese momentos tan críticos como los actuales. Está en juego su naturaleza social, no en lo declarativo, no en lo legal, sino en la práctica histórica de largos años. Está en juego participación, política auténtica, es decir vigencia al nivel de las decisiones. También, y lo más importante, está en juego poder, el de un grupo social en la sociedad; no de unos cuantos, selectos y depurados, sino de un importante sector, tal vez el más consciente clvicamente, que con amplia libertad para equivocarse, tuvo voz más o menos prestigiada, en importantes problemas del acontecer nacional.

\section{El Oculto Modelo de la Universidad Peruana}

La nueva ley orgánica no significa esta vez un simple reordenamiento o reforma de las normas que rigen la educación superior. Involucra la puesta en vigencia de un modelo coherente de institución y sistema que conlleva la transformación de las funciones básicas de la universidad dentre de la sociedad. Se puede distinguir en la ley dos temas centrales: Ia Universidad como sistema, y la universidad en lo concreto, como institución. En apretado resumen, dire- mos que se impone a nivel de la institución universidad, el esquema dilecto de la universidad contemporánea norteamericana, individualista, cientifista, neutral frente al dinamismo social, que convierte al docente en un simple funcionario desprovisio de toda participación en la decisićn y en el poder y que convalidando un moralismo estrecho y subjetivo coacta las libertades personales en aras de una pretendida eficiancia del conjunto. A nivel de la universidad-sistema, se enfatiza la contribucićn al desarrollo del país bajo la orientación del Estado, y se rescatan importantes valores como la necesidad de superar la dependencia nacional, señalando también el aporte de la universidad (Art. 3\%, inciso f). Lamentablemente, la centralización del poder en un esquema de alta racionalidad planjficadora nos ofrece el quiebre auténtico de la autonomía de larga tradición, reducida ahora la Universidad Peruana a la categoría de unidad administrativa de la actividad pública. Confrontados ambos esquemas, aparece incomprensible la contradicción flagrante entre el modelo individualista, neocapitalista y de no-compromiso de la universidad-institución, y el esquema tentativamente socializante, promocional y de medio para el desarrollo que se atribuye al sistema de la universidad. La incoherencia da margen a inierpretaciones diversas, sobre las fuentes e inspiración de la nueva ley. No interesa.

Lo auténticamente grave de la situación creada es que quienes promulgaron la ley no hayan percibido este curioso maridaje. Del conflicto entre dos tesis que se niegan no sale nada por más aspectos positivos que se quieran encontrar fragmeniande la visién global. $Y$ es que habría mucho que aplaudir: el intento de evitar la duplicación de servicios y la dispersión de esfuerzos y recursos; el establecimiento de un sistema regional de organización de las universidades; el reorcienamiento de la gratuidad de la enseñanza en términos de justicia distributiva; el reconocimiento del rol de la investigación como necesario al desarrollo nacional, la supresión del lucro como motivación en la institucionalización privada de la enseñanza superior. Otros aspectos serian igualmente aceptables y los propios principios, fines y funciones postulados a la Universidad serían suscribibles casi en su totalidad, si no se entendiera la necesidad de sustituir conceptos que implican aceptación o acuerdo con el status social vigente por otros que testimonien aleria, protesta o necesidad de cambio. Pero todo lo positivo que se pueda ubicar en los 170 artículos de la ley, o en los sólidos considerandos que la preceden, carece de 
importancia al hacerse luz sobre los modelos implícitos.

- Lo más grave resulta ser la perspectiva alienante en que ${ }^{-}$se encuadra la Universidad como institución, reafirmada por la estructura vertical y centralizada del Sistema. Este, mientras por un lado sacrifica la autono-

- mía -en aras de la coniribución a los planes de desarrollo-, por el otro, contradiciendo sus propósitos, entrega el control del conjunto a un reducido y poco representativo grupo dotado de extenso poder. Se niega asi la esencia democrática de la Universidad $\mathrm{Pe}$ ruana, que hubiera sido respetada en fórmulas de Asamblea o Federación de Universidades, que permitiesen la participación igualitaria de todas las universidades del país, tanto en la definición de la política -lo que se les niega-, cuanto en establecer la coordinación funcional que se desea.

\section{LA UNIVERSIDAD COMO SISTEMA}

Para cierto público, abierto a la teoría contemporánea en las ciencias sociales, la idea de un Sistema Nacional de la Universidad Peruana puede haber aparecido como índice de un enfoque actualizado por parte del gobierno en la comprensión de la realidad. Conviene aclarar, que el concepto de"sistema"usado en la ley universitaria no tiene el trasfondo/sociológico que algunos pudieran acreditarle, limitándose a describir un cierto tipo de relaciones adpuinistrativas. El sistema de la Universidad Peruana es lo dice la ley, "el conjunto de las Universidades del país y de los organismos de dirección y coordinación nacionales y regionales" (Art. 5\%).

La tradición universitaria confirió a cada institución -estatal o privada, en la capital o en provincias-, derechos, atribuciones y obligaciones que posteriormente la ley tradujo, respetando ritmos y procesos diferentes, y distinguiendo ciertos particularismos que cuando no significasen un privilegio odioso o una desigualdad criticable, conferían riqueza a la institución dentro de una sociedad plural. La primera crítica formal al Sistema reside en la práctica supresión de las peculiaridades, uniformizando a todas las universidades estatales y privadas, sin distinción de área (Art. 9\%). Lo hace en base a la interpretación ampliada del Art. 71 de la Constitución, que confiere al Estado la dirección técnica de la educación y a un loable criterio de introducir racionalidad en la caótica y dispersa estructura de la enseñanza superior. Las discutibles salvedades sobre las universidades particulares: -Art. $20^{\circ}$, personería jurídica; art. 24\%, limitaciones a su autonomía académica (registro de títulos) y económica (examen de presupuesto); art. 124으, exención del requisito de Decreto Supremo para la contratación de préstamos; art. $140^{\circ}$, obligatoriedad del régimen de pensiones escalonadas-, y lo genérico de las disposiciones sobre regionalización, que no se centran sobre la especificidad de las áreas, sino sobre los fines de integracićn y coordinación, que responden a otras finalidades operativas, ratifican la critica expuesta.

$\mathrm{Si}$ se deja de lado estas consideraciones pluralistas, justificando la intención socializante en ahorro de esfuerzos y coordinación de recursos, queda por discutir lo aceptable de la conversión, no sólo de la universidad como institución, sino del Sistema en conjunto, en una unidad administrativa de la actividad pública. Para sustentar este aserto conviene recordar la exposición -cuatro meses atrás- del Ministro de Hacienda sobre la reforma de la estructura de la administración pública, donde se afirmó que el responsable (en orientar y dirigir) de la política de cada Sector era el Ministro respectivo y concordarlo con la ley que se comenta, la cual en el Art. $6^{\circ}$ señala "el Sistema de la Universidad Peruana, es parte constiłutiva del Sector Educación y consecuentemente su actividad está enmarcada dentro de la Política Nacional de Educación y acorde con las conclusiones del Sistema Nacional de Planificación", y en el art. 15\%, inciso e), refiriéndose a la formulación del Presupuesto del Sistema, finaliza señalando el requisito de elevarlo al Ministerio de Educación "en su calidad de órgano central del Sector".

\section{Autonomia y Naturaleza de la Universidad}

Si la Universidad en conjunto, está supeditada no sólo administrativamente, sino que incluso la política general de su actividad se genera fuera de ella, las declaraciones sobre autonomía de la Universidad -atribuible solamente en cuanto a Sistema (art. $2^{\circ}$, inciso e) y descrita en los cuatro incisos del art. 8\%-, pierden significación, hasta el punto que puede afirmarse que la autonomía que la ley pretende respetar es una simple ficción administrativa, asimilable a la autarquía de que goza cualquier organismo funcionalmente descentralizado dentro del Estado La supeditación de la Universidad a decisiones externas, el condicionamiento de sus libertades fundamentales, de expresión y de cátedra, y el temor de un progresivo sometimiento a una ideología "oficial", manifiestan 
la cancelación de un atributo real, aún cuando nunca definido en la ley, considerado inseparable de la universidad latinoamericana en los últimos cincuenta años.

Conforme se profundiza las implicancias de la conclusión anterior, aparece lícito preguntarse si más allá de la autonomía, no se pierde algo más importante, es decir, aquello que la autonomia protegía. Es correcto aceptar que la Universidad forma parte de "la organización institucional del país" como lo afirman los considerandos del Decreto-Ley y el inciso a) del art. $2^{9}$, pero no lo es, pensar que lo sea en la misma forma que una corporación de energía, un ente regional o una autoridad portuaria. La alcurnia universitaria que le permitió a la institución ser tribuna social y ejercer una función censora de la marcha del país, le confiere una naturaleza peculiar fruto de la historia nacional, que sólo puede compararse al rol municipal y que no admite la descalificación con que la afecta el nuevo texto legal.

La necesidad del Sistema que aparece justificada como un intento de racionalización, puede cuestionarse muy seriamente si se reconoce que en el fondo no es sino una entelequia, mejor aún, un subproducto de las Universidades que son la sede real de las altas funciones de docencia, investigación y promoción social. A partir de ese reconocimiento -que la esencia universitaria reside en la comunidad específica y no en una abstracción-, el Sistema se podría entender sólo como una función de servicio, de coordinación y de racionalización, pero en ningún caso como el omnipotente instituto que establece la nueva ley orgánica. Cabe considerar un Estatuto de la Universidad Peruana como fruto de una federación nacional de universidades, producto de un concierto de voluntades autónomas, pero no como la emanación de una superestructura, de escasa base democrática. La solución da$\mathrm{da}$, de concentrar poder en el Consejo Nacional, que no libera a la Universidad de su dependencia del Poder Ejecutivo y del Sistema de Planificación, no es solución ni garantiza la autonomia. El recorte de la función crítica o rectora (art. $2^{\circ}$, inciso b) final) -tan esencial a la naturaleza de la Universidad como la de creación y transmisión cultural-, y la virtual desaparición de la autonomía, asestan a la Universidad $\mathrm{Pe}$ ruana uno de los más rudos golpes de su historia.

\section{Socialismo y Política}

La intención socializante de ligar la Universidad y la acción del Estado, y la reiteración en Ta tey de los vínculos estrechos entre la Universidad y el desarrollo del país, son elementos a ser evaluados separadamente.

Lo primero, puesto de manifiesto en los considerandos previos y en el artículo $6 \%$, antes citado, involucra una concepción del Estado con intensa participación en toda la vida nacional con metas colectivas claramente definidas, donde cabría señalar al máximo detalle la asignación de la tarea públiça. Los resultados perseguidos, (art. $3^{\circ}$ en todos sus incisos) por los valores que postutan justificarian incluso el sacrificio de ciertas libertades, en holocausto a la plena realización de un modelo de sociedad. No obstante, sin el contexto global y - teniendo como parámetro el contradictorio modelo institucional-, aplicar tal enfoque en el marco de una sola institución resulta peligroso por la verticalidad y la centralización del poder que supone, si se atiende a la naturaleza transicional, subdesarrollada y dependiente de la sociedad.

La perspectiva de supeditación a las orientaciones del Estado, se extiende veladamente a la aceptación de una ideología "oficial". Mientras aparentemente sólo se proscribe la actividad política partidaria dentro de la universidad (art. $2^{\circ}$, inciso g), la propia ley hace abiertamente política, al restringir la libertad académica y de expresión, y al constreñir a la institución universitaria - de acuerdo al inciso b) del mismo artículo-, "a enjuiciar les problemas de la realidad nacional y pronunciarse libremente (?) sobre ellos, con carácter estrictamente racional y científice y con criterio altamente constructivo". Basta romper la barrera de las palabras para percibir la concepción de universidad sometida al status actual, prohibida de ideologizar su expresión y limitada por tener que ser constructiva, es decir castrada de su función de denuncia. Conviene reiterar que el sistema social nacional no tiende ni remotamente al equilibrio -por más que el estructuralismo funcionalista de algunos científicos sociales asi lo presuma-; a la inversa, tiende a perpetuar el desequilibrio, fruto de la dominación.

La universidad prevista por la ley, recortada en su autonomia subordinada al gobierno, depurada de posición y crítica, incluso financieramente más dependiente que antes, no deja de ser sin embargo un instrumento de política, pero transforma su compromiso activo con el cambio por una no-participacion que activamente favorece a los mantenedores del inmovilismo social, La tentativa, sugerida por las disposiciones generales, de aplicar un enfoque socialista a la iarea 
universitaria, corre aquí el riesgo de disolverse en una estructura sometida y anestesiada, que resulta contradictoria a los fines que se previeron para el Sistema.

\section{Universidad y Desarrollo}

El segundo aspecto, relativo a la contribución de la Universidad a la consecución de los objetivos de desarrollo del pais (art. $3^{\circ}$, inciso a), y.al logro de una_sociedad justa, promoviendo la transformación de las estructuras (art. 3\%, inciso b), sirve para ilustrar el djvorcio frecuente entre una formulación aceptable como la expuesta, y los medios que se está dispuesto a mo. vilizar para obtener tales fines. TNo podrá contribuir la Universidad al cambio, dentro de un esquema vertical, que en su organización y procedimientos estabiece y rattflca la dommacion (del Consejo Nacional

- sobre las universidades base). Cómo lo hará si se ve privada en la práctica de las funciones de crítica social que involucran un inevitable compromiso ideológico y de interpretación de la coyuntura, de modo que el servicio a la comunidad que pide el Art. $19^{\circ}$ no sea un mero acatamiento y contribución a la socialización de las nuevas generaciones en el sistema imperante, sino el ejercicio, libre de censura, de una función tutelar que integra la investigación, la creación de ciencia, el desarrollo de la técnica y la docencia, dentro del marco amplia del compromiso social con el cambio, en pro de la iusticia.

No cabe confundir el desarrollo del país con los lineamientos de un plan para alcanzarlo. $Y$ en este error parecerían haber incurrido los redactores de la ley. Dentro de un sistema de planificación indicativa como el que parece proponerse al país, el rol de la universidad podria ser muy importante, fijando parcialmente su contribución en la elaboración de la política nacional de educación. De forma inconsistente la ley sugiere un rol diferente y somete a la universidad, a través del Consejo Nacional, a planificar su desarrollo en función de la política nacional de educación y de la planificación del desarrollo nacional (Art. 15\%, inciso c). Es decir, que la Universidad como Sistema recibe desde arriba los lineamientos sobre su desarrollo y se limita a adecuarse a ellos.

Este enfogue subordina una vez más a la Universjdad, le niega contribución - no al plan - pero_síal desarrollo. E incluso, en lo que a plan se refiere, no se percibe diálogo, sino simple supeditación (Art. $\left.6^{\circ}\right)$, lo que a más de ratificar la abolición de la autonomia, abre un peligrose cauce a la arbitrariedad. La dictadura funcionaria, venga del Ministerio de Educación o del Sistema de Planificación, tendría como única consecuencia la esterilidad de la Universidad. De este modo y de allí la crítica, la contribución al desarrollo que se le señala a la Universidad es muy instrumental, cuando se pasa de lo declarativo a lo cončréfo. Nuevamente, ef recorte a la opinión, el enmarcamiento en el guión oficial, el supuesto de que el desarrollo son los objetivos que el plan señala o la incongruencia entre la promoción del cambio de estructuras y la crítica "altamente constructiva", rebajan el rol a que la Universidad tiene derecho, de participar en la estructura de poder nacional y en la Política, contribuyendo así al dinamismo social que oriente el cambio y el desarrollo.

\section{Juicio Político del Sistema}

Cabe cerrar este capitulo con un enjuiciamiento de las consecuencias que pudieran derivarse de la entrega de un volumen de poder tan amplio al Consejo Nacional de la Universidad Peruana, integrado en su primera etapa por un cuarto de los Rectores de las Universidades existentes. Las facultades de dar y modificar el Estatuto, establecer la estructura regional del Sistema, planificar el desarrollo de la universidad, decidiendo sobre la creación o supresión de programas académicos (ex-Facultades), asignar responsabilidades de investigación, formular el presupuesto del Sistema y elevarlo al Ministro de Educación, dictaminar sobre la creación y supresión de universidades, establecer un sistema de evaluación y categorización de las universidades, resolver los conflictos al interior de las mismas pudiendo incluso disponer la reorganización y/o el receso, son en apretada síntesis la expresión del poder y responsabilidades centralizadas, y al parecer en última instancia, que el Art. $15^{\circ}$ confiere al Consejo Nacional. Por extensión de lo dicho antes y a tenor de la noción de Sector, el Gobierno se reserva la decisión en políticas y presupuesto, amén de haber declarado expresamente la Ley (art. 25\%) que la autonomía "no es un derecho de extraterritorialidad", derogando así la tesis de la inviolabilidad del "campus", otro instituto real, aunque no legal, respetado por una tradición de largos años.

Retornando a la distribución de poder en el Sistema, se encuentra que la regionalización prevista resulta adecuada en una perspectiva administrativa por cuanto crea una unidad de programación y una instancia decisoria intermedia; la centralización de funciones a nivel nacional, acusa grave peligro. Se hace responsa- 
ble a la Universidad por ella misma, en su Consejo Nacional, a un grado no visto. Significa esto una contradicción frente a la supresión de la autonomía que se ha develado anteriormente? Por el contrario. El poder que se confiere está estrictamente delimitado y es dependiente. No es representativo porque no emana de las bases y no hay control sobre su ejercicio. $\mathrm{Ni}$ siquiera se prevée una Asamblea Nacional o mecanismo similar.

En un sistema social inestable y de alta politización - por más decretos o leyes que la proscriban-, un exceso de responsabilidad puede significar el destrozamiento interno de la institución o el más completo sometimiento del sistema al gobierno central. Como ejemplo, el haberle entregado la responsabilidad presupuestal al Consejo Nacional -en momentos que se invierte el proceso natural en el Presupuesto Funcional o por Programas y se exige que los gastos se recorten al nivel de las disponibilidades, restringiéndose la iniciativa de las unidades de asignacićn en la base-, debe derivar naturalmente en competencia quizá poco caballeresca por lograr una mejor tajada de la recortada partida presupuestal, librándose la decisión al Consejo Nacional sin que las universidades no representadas tengan medio de control ni instancias de revisión. Caso similar to plantea el hecho de que la atribución legislativa de crear y suprimir universidades haya sido transferida en la práctica (Art. 22\%, concordante con el inciso $\mathrm{g}$ ) del Art. 15\%) al propio sector interesado, liberando al Gobierno de la decisión. Lo mismo ocurre con otras fuentes de fricción y tirantez cuales son el sistema de evaluación y categorización de universidades y el mecanismo de resolución de conflictos.

La Universidad Peruana como Sistema y su Consejo Nacional de Rectores designados -de no modificarse la ley sustantivamente- requieren un alto grado de percepción para identificar la alternativa que enfrentan: o abdican completamente su autonomía y con el concurso del gobierno se someten sin discusión a la ley, aceptando la responsabilidad histórica de traicionar su rol esencial, o caso contrario, si permiten que el conflicto por el poder se estructure, ya sea por problemas presupuestales, por incapacidad de reprimir o canalizar la discrepancia, o por simple incapacidad de dirigir una institución tan compleja, arriesgan la ingerencia definitiva del Gobierno que encontrará justificada la intervención o el receso de la universidad por no saber auto-gobernarse.
No hay escapatoria. La ley en su texto actual no permite el auto-gobierno. No tratar de rescatarlo implicaría sacrificar valores demasiado caros a la esencia universitaria. Lamentablemente, el no logrado modelo socializante, invalidado en sus contradicciones internas, falto de coherencia con la realidad que circunda a la Universidad, la entrega inerme a los claros objetivos del modelo institucional, y no resuelve la seria disyuntiva anterior.

\section{LA UNIVERSIDAD COMO INSTITUCION}

El hecho que la Universidad en conjunto, rebajada en su categoría institucional y sometida a las políticas que le sean impuestas desde arriba, pueda $\sin$ embargo aparecer funcional para los objetivos del gobierno, resulta incomprensible si se analiza las implicancias - tal vez no percibidas- de la transformación que opera la ley en las universidades como instituciones concretas y particulares, más allá de la descalificación contenida en el art. 19 ${ }^{\circ}$ que definiéndolas como entidades de servicio a la comunidad, las reduce a simples "bases funcionales y administrativas" para el Sisiema.

\section{Dependencia Cultural, Ciencia Propia y Universidad}

Hay supuestos sin los cuales el análisis que sigue carecería de sentido; afortunadamente el consenso sobre ellos es muy amplio. El primero es la afirmación de que el pais vive una acusada dependencia cultural de tendencia progresiva. Para un porcentaje demasiado alto de profesionales, actualizar el conocimiento y Tograr la ciencia que el desarrollo del país requiere, es simplemente provocar una 'modernización refleja', consistente en la aceptación pasiva de los frutos de un saber ajeno, sin cuestionar mayormente su condicionamiento por circunstancias e historia diferentes. Quienes así raciocinan se inscriben con frecuencia en la aceptación de la tesis según la cual el desarrollo de la sociedad será logrado a partir de un proceso de 'difusićn cultural' que se genera en los paises más adelantados. Según esta hipótesis, la historia del progreso es unilineal, es decir que a los países más atrasados no les queda otra salida para acelerar su desarrollo, que aceptar la ciencia y la técnica ya perfeccionada, por cuanto volver atrás o pretender vias alternativas carece de sentido.

Como consecuencia de tal enfoque, el 'cientííico' en un país como el Perú, no se esfuerza por crear, expe- 
rimentar y teorizar, sino que limita su función a permanecer atento y al día sobre lo que otros producen, escriben y elucubran. Es decir, vive alienado en la conviccićn de que sin los recursos de equipo, biblioteca o instrumental que se le ha enseñado a reverenciar, todo su esfuerzo sería vano. Lo que es tan trágicamente ostensible en las profesiones técnicas -que como resultado de la frustración arrojan las más altas proporciones de evasión, en la migración proiesional a los países desarrollados-, resulta mucho más grave - por el rol que ocupan en la sociedad-, en la claudicación de los científicos sociales que enfrentados a la exigencia de interpretar una realidad, sacrificando la dura, difícil pero ineludible tarea de construir teoria propia, prefieren aceptar el camino fácil de reposar en los modelos sobre la situación y dinámica social de los países subdesarrollados, construidos para el consumo de los mismos por los científicos de los países cultural, política y económicamente dominantes.

Un segundo supuesto del análisis, complemento y consecuencia del anterior, es el derecho que la sociedad peruana tiene a una ciencia y a una cultura propias. Cuando se acepta definir al país como fragmentado cultural y socialmente, subdesarrollado en todos los órdenes como consecuencia o epifenómeno de los procesos de neo-colonialismo, dependencia externa y dominación interna, debe aceptarse también que lo peculiar de tal condición requiere respuestas identificadas con el interés nacional, que poco o nada tienen que ver con los modelos supuestamente no ideológicos formulados en el extranjero. Demasiadas ve-. ces se ha denunciado la paradoja en las recomendaciones sobre el desarrollo nacional generadas en los paises dominantes: la existencia de un modelo de sociedad en equilibrio que ignora las desigualdades y enfrentamientos, el supuesto del progreso exclusivamente a través de la producción industrial automatizada, el énfasis en la producción de bienes últimos, incluso con insumos importados, etc. que revelan dos cosas igualmente graves: la inconsistencia de la propuesta por inadecuación a las condiciones que la realidad impone, ignorancia de los recursos disponibles y las capacidades de consumo, o lo que seria mucho más grave el intento de orientar el país hacia un modelo de sociedad por el cual nadie ha optado, pero que interesa vender - por razones múltiples y de ética variable- a los dirigentes y a la masa, en acción hábilmente concertada.
De los presupuestos anteriores fluye el rol de la Universidad. Es el único instrumento cie que disponemos para emanciparnos de la dependencia cultural. Más allá de ser la conciencia social de la nación es la expresión concreta y el testimonio del compromiso activo de la sociedad con el desarrollo, en términos de liberación del hombre. Es su tarea construir la ciencia y la tecnología que se requiere para ello. Significa desplazar el énfasis, de la contribución a la ciencia universal, a una respuesta a la problemática del hombre peruano, aqui y ahora. Significa abiertamente reconocer la ideologización de la búsqueda científica en la medida que el compromiso sea superar los desequilibrios e injusticias que objetivamente se atestiguan. Significa reemplazar la llamada ciencia libre, dependiente del capricho o interés del investigador, árbitro individual del interés y la enseñanza profesionalista, por una ciencia y una docencia 'sociales' es decir condicionada por las urgencias, disponibilidades y recursos de una sociedad que no puede tarse el lujo de derrochar o malgastar.

Todo lo anterior representa el ejercicio de un derecho. Podría decirse que está recogido en los considerandos del Decreto-Ley 17437, sin embargo, el texto de la ley impide su instrumentación. La universidad como institución debe ser celosamente protegida de las sutiles formas que puede afectar la alienación. La ley en la coherencia del modelo inscrito en su Título Tercero, abre una compuerta amplia que es obligatorio exponer ante quienes ejercitan facultades que podrían rectificar tan grave error. No es concebible que a un gobierno de postulados nacionalistas, actitudes soberanas y en ciertos casos anti-imperialistas, y que pretende estructurar una estrategia de largo plazo para desarrollar al país en base a sus escasos recursos, se le sorprenda al sometérsele un instrumento legal de tanta trascendencia, que bajo la cubierta de eficiencia, diversificación de funciones, seriedad académica, apolitización y otros valores ciertos o presuntos, esconde un concepto de universidad_individualista, no comprometida, sin función social y científicamente dependiente.

El modelo de universidad definido entre los artículos $19^{\circ}$ y $121^{\circ}$ del Decreto-Ley se percibe principalmente a través de tres problemas centrales: el divorcio entre las funciones de gobierno y la actividad académica/el rol dependiente de la docencia/y la presencia apenas simbólica del estudiante en la comundad universitaria. 


\section{a) Separación gobierno-actividad académica}

El Capítulo Segundo del Título Tercero de la ley señala en orden jerárquico que los órganos de gobierno de cada universidad serán la Asamblea Universitaria, el Rector y el Consejo Ejecutivo. La Asamblea es un cuerpo fundamentalmente deliberante, no tiene derecho de iniciativa, debe limitarse a ratificar en algunos casos, aprobar o rechazar en otros y actuar directamente sólo en lo que a elección del Rector y ViceRectores se requiere. El poder se concentra en el Rector y el Consejo Ejecutivo que prácticamente no se diferencian, en la medida que el segundo es emanación del primero. En efecto, de acuerdo al procedimiento establecido (Arts. $44^{\circ}$ a $47^{\circ}$ ), el Rector nombra a los directores universitarios (o Jefes de Sistemas en el lenguaje de los especialistas en organización), quienes salvo el caso de que la Asamblea no los ratifique -circunstancia en que el Rector no pierde la iniciativa y los sustituye-, conforman con él mismo y los Vice-Rectores el Consejo Ejecutivo. Para los efectos académicos este Consejo se completa con los Directores de Programas Académicos (equivalente de los anteriores Decanos de Facultades, pero sin responsabilidades administrativas), que también requieren ratificación de la Asamblea en su nombramiento, originado en el propio Consejo Ejecutivo. Los profesores y estudiantes, que en el régimen anierior tenian asiento en el Consejo Superior, carecen de toda representación.

La centralización y concentración de poder son desproporcionadas. Con la sola excepción del Rector y los Vice-Rectores, no hay más personal elegido en forma directa. El mecanismo de ratificación tampoco confiere mayor poder ni control a la Asamblea donde si hay presencia docente--, ya que en el caso de rechazo a una propuesta, la vacancia de un cargo no inhibe el funcionamiento del Consejo, y en todo caso, el sustituto propuesto puede actuar sin restricciones por todo el tiempo que transcurra hasta la próxima reunićn de la Acamizles cionde cabría solicitar su ratificación (Art. $47^{\circ}$ ). Además, con independencia del procedimiento, lo que define el poder del Consejo Ejecutivo son las atribuciones que el Art. $44^{\circ}$ le encarga, y que abarcan desde la formulación del reglamento general, los planes y los presupuestos, hasta el nombramiento y la contratación de profesores, pasando por la facultad de recesar la universidad, resolver los conflictos internos y establecer el régimen disciplinario. Los administradores de este poder son, en primera instancia, los Directores Universitarios a cargo del equipo de funcionarios requeridos para implementar áreas como las que explícitamente detalla la ley: planificación, investigación, personal, evaluación pedagógica y servicios académicos, economía y servicios administrativos, bienestar universitario y asuntos estudiantiles y proyección social de la universidad.

La sistemática de la ley, que dentro del Título Tercero distingue nueve capítulos diferentes, no permite percibir con claridad la forma en que el nuevo esquema de funcionamiento afecta al conjunto de la universidad. Se sostiene por los defensores del modelo que la independización practicada de las responsabilidades administrarivas, es una 'liberación' del profesor, que puede ahora dedicarse con entera tranquilidad a la docencia y a la investigación. Más aún, se hace hincapié en el hecho de que tal medida no vulnera la preeminencia de la función académica, dado que los responsables de los sistemas administrativos -es decir los Directores Universitarios- están sujetos al requisito 'sine qua non', de ser profesores principales para acceder al cargo. Lo que no se percibe por quienes así razonan es que la separación entre gobierno interno y régimen académico va mucho más allá de la mera distinción entre dos sistemas de administración singular. No se trata de que el profesor se sienta particularmente interesado en desempeñar cargos administrativos y ser elegido a ellos. Lo que ocurre es que esa participación en organismos de gobierno, que ahora se le recorta o niega, es una valiosa fuente de poder y el respaldo efectivo de su compromiso docente.

La evolución histórica - no legal- de la Universidad, exigió la superación de la docencia orientada al profesionalismo individualista en aras de una mayor dedicación del profesorado a la universidad, el abandono de un humanismo ineficiente a favor de un racionalismo científico pero sobre todo, la adquisición de un compromiso entre la docencia y el ser social de su tiempo, encarnándose este compromiso en definición personal, opción ideológica y riesgo. La universidad, refugio durante largo tiempo de reformadores sociales de la más diversa índole, pudo cumplir mal que bien una misión profética respecto a la sociedad en la medida que garantizó al docente comprometido libertad que estimulara su creatividad, y seguridad a través de mecanismos de representación con poder suficiente. Es verdad que también garantizó la estabilidad de grandes sectores de profesorado indiferente, para los que la Universidad es un medio de vida y no una tarea en sí, pero este riesgo es inseparable de su vocación 
democrática. La Ley Orgánica de la Universidad Peruana, al establecer únicamente una participación nominal del profesorado en la Asamblea, organismo que a su vez tiene un escaso poder deliberativo, y excluirla del Consejo Ejecutivo, recorta de hecho el ámbito de libertad del docente.

La separación expuesta consagra un desequilibrio. Independientemente de la diversidad de las funciones, da poder a unos -los administradores- en desmedro de otros. La funcionalidad buscada debió complementarse con adecuada participación en el poder que garantizando control ratificara la esencia democrática de la Universidad. La libertad de enseñanza y de investigación, sin estructura democrática de gobierno, son un mito. Entendido desde luego que esta libertad concierne a los medios, y que en ningún caso quiere decir libertad indiscriminada - de acuerdo al concepto clásico- en la medida que la Universidad interprete las necesidades de su contexto social y oriente las áreas de investigación y docencia.

\section{b) El rol dependiente de la docencia}

El divorcio denunciado entre los sistemas académico y de administración, implica pues, a la inversa de lo afirmado en el Art. 49 ${ }^{\circ}$, la subordinación en la práctica del primero al segundo. Para los profesores, que encarnan el elemento permanente de la docencia y la investigación, significa una estratificación injustificada y la pérdida de participación en el poder y la decisión que los afecta, en abierta contradicción a las teorías contemporáneas de participación. Por último, representa la supresión de derechos ejercitados por largo tiempo que constituían el sustento legítimo de un compromiso personal que hoy aparece inerme frente a la arbitrariedad eventual de la autoridad.

Pero el ejercicio del rol docente se ve amenazado desde ángulos menos evidentes. El Art. $52^{\circ}$ de la ley declara que la organización académica de la universidad responde a un criterio funcional, que esa funcionalidad está determinada por el logro de la integración de la actividad universitaria y el evitamiento de la duplicación innecesaria de esfuerzos y recursos y que, como consecuencia, la universidad está conformada por unidades académicas llamadas Departamentos. La disposición anterior ha sido calurosamente celebrada. Universidades que ya habian adoptado la departamentalización, o se hallaban en proceso de implementarla, no han demorado en expresar su conformidad con este importante capítulo del texto legal. $Y$ en efec- to, a primera vista, el enfoque resulta casi inobjetable. Se trata de una racionalización de la actividad académica que evite la proliferación de micro-núcleos de conocimiento dentro de cada programa de formación profesional o académica. La propuesta es que los componentes de la universidad, docentes, curriculos y estudiantes, se agrupen no en aras del profesional:smo sino de las consistentes divisiones de los campos del saber. Los departamentos resultan en este contexto, y la ley lo explicita también, "núcleỏs operacionales de investigación, enseñanza y proyección social que agrupan a profesores que cultivan disciplinas afines".

La crítica a este aspecto de la nueva ley es sólo parcial y tentativa, en base al argumento central antes expuesto: la adhesión del texio legal a un modelo foráneo de universidad, inadecuado a la coyuntura que vive el Perú. En algunos países europeos y en Norteamérica, donde la universidad no ejercióo nunca la función de crítica social que cumplió en Latinoamérica en este siglo, y donde el proceso de integración de la sociedad involucró dinamismos diferen tes, la filosofía neo-positivista predominante estableció un criterio de funcionalidad basada en la contribución de todas las ramas del saber a una ciencia global de acceso abierto, en la cual la visión resumen quedaba en manos de los detentadores del poder y guias de la sociedad. Dentro de esta perspectiva no es función particular el tentar interpretaciones de conjunto, y el profesor como el investigador limitan su participación activa y pasiva a las áreas propias. La metodología misma de la ciencia está organizada de forma de atender eficientemente este objetivo. La premisa inicial necesariamente está representada por la convicción de que hay una utopia consistente que guía al hombre, a partir de la cual se define la funcionalidad de cualquier hecho social.

La pregunta derivada de lo anterior seria: en qué medida la departamentalización de la universidad peruana, es funcional - no para una mayor racionalización, que supone el modelo implícito-, sino para el cumplimiento del rol de la universidad en la sociedad peruana. Si lo que se exige del docente y de la universidad es compromiso social, participación en el desarrollo, comprensión totalizadora del pais, la departamentalización puede no ser una respuesta positiva, sino más bien un nuevo mecanismo de alienación, esta vez a favor de una ilusoria contribución al conocimiento universal. 
La visión disminuida del rol docente no se limita al mecanismo de alienación al que se le expone, ni a la pérdida de participación antes señalada. El capítulo de la Ley sobre personal académico, que tiene excelentes aportes al establecimiento de una carrera docente, destruye el principio de seguridad y permanencia - tan ligado al servicio público-, e introduce un criterio de coacción subjetiva inaceptable, al disponer en el Art. $82^{\circ}$ que como causales de separación de sus funciones se consideren "d) observar conducta inmoral o gravemente reprensible", "e) infracción y/o inobservancia de la Ley" y "f) realizar activismo o proselitismo político partidario dentro de la Universidad". No es difícil preveer el género de comporiamiento que estas disposiciones puedan generar, institucionalizando la "soplonería" y la difamación o la acusación gratuita, todo ello en único desmedro de la Universidad y la dignidad docente.

Como aporte válido, aún cuando polémico de la Ley puede señalarse el arraigo local de la universidad y sus profesores, establecido en los artículos $61^{\circ}$ y $77^{\circ}$ de la ley. Al igual que en ejemplos anteriores, esta medida puede resultar de doble filo. La intención evidente es frenar el crecimiento anárquico y falseado de las universidades de provincias que venian funcionando con el sistema de 'sucursales', desprovistas de docencia permanente y alquilando profesores de las universidades mayores. Lo anterior, justificaba un reordenamiento que dentro del criterio de racionalidad establecido por el gobierno, aparece en completa consonancia. Interesa señalar que hay otra perspectiva que posiblemente quienes formularon la ley no tuvieron en consideración. La universidad de provincia en un pais como el Perú, no puede ser mensurada con los mismos criterios que las patriarcales universidades mayores o las modernas instituciones de origen privado. El rol que cumple es radicalmente distinto. Posiblemente no contribuye a la creación de ciencia, ni a la investigación, la enseñanza es deficiente y su profesorado no se encuentra absolutamente motivado o comprometido. En cambio de eso, es un vehículo altamente eficiente para que se mantenga en vigencia procesos necesarios de participación y movilización social. Si no se acepta un rol diferente de acuerdo a realidades heterogéneas, la aplicación simplista de un criterio de modernización, ofrece como consecuencia adicional a la calificación negativa, una discutible estratificación institucional, que cabría corregir con criterio compensatorio, pero no con la simple eliminación de instituciones.
La idea de un rol propio a la universidad continúa como el criterio esencial para diagnosticar la multitud de elementos dispersos en la ley, susceptibles de recibir entusiasta y tal vez apresurada aprobación. En el régimen de estudios, a más de la departamentalización y la tendencia a la docencia de tiempo completo, la introducción de cursos propedeúticos al inicio de toda enseñanza universitaria (Art. $87^{\circ}$ ), la autorización amplia al sistema de créditos (Art. 95\%), el curriculum flexible (Art. 94\%), y las áreas de especialización graduada (Art. 89.) $^{\circ}$, significan en la práctica la satisfacción por la ley, de la mayoría de aspectos que el profesorado "modernizado" ha venido solicitando luego de dejarse encandilar por la imagen de alta eficiencia proyectada por la universidad norteamericana. La objeción de que el Perú no se encuentra en condiciones de afrontar los altísimos costos que demanda este tipo de reforma académica sin tener que incrementar su endeudamiento externo (convenios AID, BID, Fundación Ford, etc.), puede ser respondida simplistamente o con demagogia, diciendo que el país debe sacrificar lo que sea necesario por una mejor educación. La pregunta obsesiva que aquí se repite es si no existe más que un modelo ineluctable de universidad hacia el cual se pueda tender, y si en atención a ella debe aceptarse todos sus ingredientes.

\section{c) El sometimiento del estudiante y su rol pasivo}

Este análisis de conjunto, sin pretensiones de exhaustivo, no podría dejarse sin hacer referencia a la concepción del estudiante implícita en la ley. El Art. 107\% al enunciar formalmente una concepción de lo que la matricula representa como acto voluntario de adhesión y acatamiento a las normas que rigen la universidad, abre paso a la interpretación y rechazo radicales que el estudiantado ha hecho públicos sobre la ley. El mismo artículo señala que la condición de estudiante universitario "conlleva la observancia de un elevado nivel de comportamienio (?) y dedicación a los estudios y actividades de la universidad". La definición citada, teñida de conformismo, acatamiento y subordinación a las virtudes del estudio como el único criterio aceptable, revela valores discutibles, aparte de ignorancia lamentable sobre las actitudes y el comportamiento de la juventud peruana, difícilmente alterables por decreto.

La condición de estudiante, como más adelante la representación estudiantil (Art. 108\%), en la que no aparece el legítimo término "participación" y que se 
reglamenta de manera desusada que deforma la noción misma de representación; el derecho de asociación (Art. 110\%) que explícitamente margina la organización gremial, base indiscutida del movimiento estudiantil en toda su historia de lucha por la Reforma Universitaria; y la gratuidad de la enseñanza (Art. 138\%), reposan para los redactores de la ley en la idea de que el valor más alto que debe orientar al estudiante es el rendimiento; en términos más sociológicos y que acusan igualmente el modelo en el que se inspiran: la motivación del logro. Hacer tal asunción de la manera que sea, es ignorar la historia y la importancia de la participación estudiantil. La gravedad de legislar por encima de las realidades sociológicas, que puede originar serios tropiezos en la implementación o puesta en práctica de la ley, resulta insignificante al lado de la injusticia que se comete con el movimiento estudiantil - por encima de las múltiples deficiencias que se puede atribuirle-, al negarle reconocimiento y participación, cuando se hace evidente para cualquier observador imparcial que la presencia de los estudiantes en los organismos deliberativos y de gobierno fué en muchos casos el único estimulante para una sensib:lización de la universidad a los problemas de enseñanza y a las responsabilidades y compromiso de la universidad con el proceso nacional. La representación regimentada de los estudiantes en la Asamblea según la nueva ley, margina las funciones de control permanente $y$ atento, y estímulo constante que -aunque deformadas por la forma en que a veces se ejercitaron y los intereses o pasiones que suscitaron-, representan la contribución positiva del co-gobierno.

La idea de una universidad pasiva, conformista, prácticamente sin aristas a nivel del estudiantado, proyecta una sombra temible sobre el futuro de los profesionales nacionales. Si se concuerda esto con las insinuaciones de los Arts. $132^{\circ}$, inciso e) y $133^{\circ}$, inciso c), que en cuanto al régimen económico aparecen tendientes a modelar la universidad a imagen de las corporaciones de la empresa privada, dependiendo justamente de esta última para la "venta de los productos generados por su propia actividad" y de la prestación de servicios, o la disposición del art. 179 (participación de la empresa privada en el Sistema, a nivel regional), cabe preguntarse si el gobierno ha reflexionado de manera suficiente sobre el producto final -en términos de ciencia y egresados, en cuanto profesio- nales y ciudadanos-, que el pais necesita y quiere obtener.

\section{CONCLUSION}

Retomando las afirmaciones centrales, se encuentra que el Decreto-Ley 17437 coloca a la Universidad Peruana en la grave obligación de ir más allá de la letra de la Ley, para develar el espíritu que la inspira y pronunciarse al respecto, sin más criterios rectores que los altos intereses de la propia Universidad, cuya naturaleza y misión esencial están en juego.

La fidelidad a la esencia universitaria, en términos de no abdicar su función de crítica social y garantizar un ámbito de libertad y dignidad a sus miembros - unida a la fidelidad al país, expresada en un compromiso social, que tienda a la liberación integral del hombre peruano y a la superación de los procesos de dependencia externa y dominación interna que reafirman la condición de subdesarrollo del país, todo lo cual está expresado en los considerandos y disposiciones generales de la nueva ley-, obligan a denunciar las incongruencias $y$ contradicciones que frustran en el texto legal tales finalidades y demandar su modificación.

Tal postura involucra para la Universidad un deber ser, una actitud crítica consigo misma que no postula el retorno a la situación anterior, ni la derogatoria simple de algunos artículos de la nueva ley, sino la determinación del modelo institucional que sea congruente con los intereses del pais, y la incorporación de disposiciones que consagren las obligaciones, atribuciones y derechos que la tradición y la historia, es decir su propia trayectoria como institución en la sociedad, le han conferido.

El consenso que el país requiere de todos los sectores, que han manifestado asumir un compromiso de transformar la situación social del país y procurar su desarrollo, exige que el Gobierno desatienda argumentos interesados en el inmovilismo y que practicando un cuidadoso cotejo de sus planteamientos principistas con el texto y el espíritu de los 170 artículos de la ley orgánica, y en estrecho diálogo con la comunidad universitaria, reexamine los conceptos incorporados, suspenda la vigencia de la ley y proceda a una cuidadosa reformulación. 